\title{
Economias de Escala e Eficiência Econômica na Produção de Laranja no Estado de São Paulo ${ }^{1,2}$
}

\author{
Marcelo José Carrer ${ }^{3}$ e Hildo Meirelles de Souza Filho ${ }^{4}$
}

\begin{abstract}
Resumo: Esse trabalho teve como objetivos investigar a existência de economias de escala e ineficiência de custo na produção de laranja no estado de São Paulo. Para tal, foram coletados dados primários junto a uma amostra aleatória de 98 propriedades rurais. Os dados foram analisados por meio de um modelo econométrico de fronteira estocástica de custo com a forma funcional translog para representar a tecnologia de produção. Verificou-se a existência de significativas economias de escala para níveis baixos/médios de produção (até 40 mil caixas), as quais vão se esgotando até surgirem deseconomias de escala para níveis de produção superior a 300 mil caixas de laranja. A escala de custo médio mínimo encontra-se entre 150.000 e 300.000 caixas. Os índices de eficiência de custo estimados mostram que há espaço significativo para ganhos de eficiência e que as propriedades mais eficientes da amostra são mais intensivas em capital. Conclui-se que as propriedades rurais podem melhorar seus resultados econômicos a partir de alterações na escala e na alocação dos fatores de produção.
\end{abstract}

Palavras-chaves: Economias de escala; Eficiência de custo; Citricultura.

Abstract: This study aimed to investigate the existence of economies of scale and cost inefficiency in citrus production in São Paulo State. To this end, primary data was collected from a random sample of 98 citrus farms. Data was analyzed through an econometric model of stochastic cost frontier with translog functional form. It was found the existence of significant economies of scale for low/medium production levels (up to 40 thousand boxes). Diseconomies of scale for production emerge for production larger than 300 thousand boxes. Minimum average cost is between 150,000 and 300,000 boxes regarding production levels. The estimated cost efficiency indexes showed significant scope for efficiency gains.

1. Data de submissão: 29 de maio de 2015. Data de aceite: 10 de dezembro de 2015 .

2. Os autores agradecem o suporte financeiro da Fundação de Amparo à Pesquisa do Estado de São Paulo (auxílio regular Fapesp 2013/06169-7).

3. Instituto Federal de Educação, Ciência e Tecnologia de São Paulo. São Carlos, SP, Brasil. E-mail: marcelocarrer@ifsp.edu.br

4. Universidade Federal de São Carlos. São Carlos, SP, Brasil. E-mail: hildo@dep.ufscar.br 
The most cost efficient farms in the sample are capital intensive. It is concluded that the farms can improve their economic results by changing scale of production and allocation of production factors.

Key-words: Scale economies; Cost efficiency; Citrus production.

\section{Introdução}

O Brasil é o maior produtor mundial de laranja, sendo que o estado de São Paulo foi responsável por $74 \%$ da produção nacional de 17,549 milhões de toneladas em 2013 (IBGE, 2013). Em que pese a importância da atividade citrícola para a economia brasileira, desde o início da década de 2010 a citricultura passa por períodos de crise e forte instabilidade financeira, com consequente redução na área em produção e saída de milhares de produtores da atividade. Segundo Neves (2010), o número de citricultores independentes no estado de São Paulo passou de 15.000, em 2001, para 12.627, em 2009. Dados da Conab/Cati/IEA (2013) mostram que na safra 2013/14 o número de citricultores caiu novamente para 10.100. Neste mesmo período, houve redução de $23,8 \%$ na área em produção, a qual passou de 609.475 hectares (ha), em 2000, para 464.447 há, em 2013 (CONAB/ CATI/IEA, 2013). Em pesquisa com 123 citricultores do estado de São Paulo, Turra et al. (2015) verificaram que, diante de preços baixos, altos custos de produção, incidência de greening e alto nível de endividamento, a citricultura não tem sido economicamente viável para $83 \%$ da amostra. A inviabilidade econômica pode continuar levando à saída de produtores da atividade.

Diferentes hipóteses têm sido utilizadas para explicar o cenário de crise na citricultura e a consequente saída de produtores da atividade, como por exemplo a redução na demanda da agroindústria processadora em decorrência do aumento da produção de laranja em seus pomares próprios (integração vertical parcial), a redução no preço da laranja como resultado da queda no consumo mundial de suco de laranja e, principalmente, as ineficiências econômica e de escala das propriedades rurais (NEVES, 2010; FIGUEIREDO et al., 2013).

Para Neves (2010), a atividade citrícola é caracterizada por significativas economias de escala, o que, por sua vez, implica em vantagens competitivas para as grandes propriedades. Utilizando dados do Lupa $(1995,2007)$, Fagundes et al. (2010) constataram que o percentual de plantas em unidades de produção com mais de 100 mil pés de laranja aumentou de 28\% em 1995/96 para $42 \%$ do total das plantas em $2007 / 08$. Nesse mesmo período, as unidades de produção com até 20 mil pés (pequeno porte) tiveram redução de $40 \%$ para $28 \%$ do total das plantas de laranja do estado de São Paulo. Dados mais recentes da CDA (2012) mostram que 347 propriedades de grande porte (com mais de 100 mil pés de laranja) concentravam, em 2012, 47\% do total das árvores do cinturão citrícola paulista, à medida que as 13.447 pequenas propriedades (com menos de 10 mil pés de laranja) possuíam apenas 17,5\% das árvores do cinturão. Esses dados indicam que grande parcela da produção de laranja do estado de São Paulo está se concentrando em grandes 
propriedades rurais 5 . Ademais, ao comparar o tamanho médio de uma unidade de produção de laranja com base nos dados do Lupa $(1995,2007)$, verifica-se que, em 1995/96, a média era de 24,13 ha e, em 2007/08, de 35,79 ha (aumento de 48,3\%).

Os dados apresentados no parágrafo anterior confirmam uma tendência de concentração da produção de laranja em propriedades rurais com maior escala de produção, o que permite levantar a hipótese de que há economias de escala para níveis baixos de produção. Entretanto, não foram encontrados estudos que testassem essa hipótese a partir de estimativas econométricas de funções de custo, utilizando dados observados nas propriedades citrícolas em produção. Dentro desse tipo de abordagem, que tradicionalmente está fundamentada na teoria microeconômica neoclássica, encontra-se a estimativa de fronteiras de custo, na qual assume-se que a função estimada representa o custo mínimo para os diferentes níveis de produção e preços pagos pelos fatores de produção (COELLI et al., 1998). Por meio da estimativa de fronteiras de custo, pode-se identificar não apenas a existência de economias de escala, mas também o nível de eficiência/ineficiência econômica de cada propriedade com base nos padrões de eficiência determinados pela fronteira. Portanto, a realização de estudos desse tipo contribui não apenas para a identificação de escalas ótimas de produção, mas também auxilia na gestão das propriedades menos eficientes. Esses fatores são fundamentais para a atividade citrícola, que, conforme já destacado, passa por significativas alterações técnicas e econômicas desde meados da década de 2000.

Nesse contexto, o presente trabalho tem como objetivos investigar a existência de economias de escala e de ineficiência de custo na citricultura do estado de São Paulo. Para tal, foram coletados dados primários junto a uma amos-

5. A diferença entre os dados da CDA (2013) e aqueles apresentados por Neves (2010) e Conab/Cati/IEA (2013) se justifica devido ao fato de a CDA apresentar informações para o número de propriedades rurais, enquanto que Neves (2010) e Conab/Cati/IEA (2013) apresentam dados para o número de produtores. tra aleatória representativa de 98 fazendas produtoras de laranja localizadas no estado de São Paulo. Adotou-se o modelo de fronteira estocástica (AIGNER et al., 1977) e a forma funcional translog para estimar os parâmetros da fronteira microeconômica de custo. O trabalho inova ao investigar a existência de economias de escala e os diferenciais de eficiência econômica de custo com base em dados de propriedades citrícolas e em métodos de análise econométrica. Os resultados do trabalho poderão ter grande utilidade para a formulação de estratégias privadas e políticas públicas.

$\mathrm{O}$ artigo está dividido em quatro seções além dessa introdução. A próxima seção apresenta o referencial teórico necessário para a compreensão da análise de fronteiras e índices de eficiência de custo, bem como uma exposição teórica da forma funcional translog. Na terceira seção apresentam-se a amostra de propriedades rurais analisadas, as variáveis consideradas na análise e o modelo econométrico de fronteira estocástica de custo. A quarta seção apresenta e discute os resultados encontrados, com ênfase nos índices de economias de escala e de eficiência de custo das propriedades rurais. Por fim, a quinta seção mostra as implicações, limitações e algumas sugestões para estudos futuros.

\section{Referencial teórico}

O referencial teórico deste artigo está dividido em duas subseções. A primeira, baseada na teoria de fronteiras de eficiência, formaliza os conceitos de fronteira de custo e eficiência de custo. $\mathrm{Na}$ segunda subseção, apresentam-se as características da função de custo translog que será estimada.

\subsection{Fronteira de custo}

A teoria microeconômica neoclássica pressupõe que as firmas possuem o objetivo de maximizar o lucro e/ou minimizar os custos de produção sujeito às restrições tecnológicas. Um 
dos postulados da teoria microeconômica é o de que as firmas operam de forma tecnicamente eficiente. Assume-se que as firmas escolhem combinações eficientes dos fatores de produção diante da tecnologia de produção disponível, o que é representado pelas isoquantas da teoria da produção. Desta forma, as firmas produzem em algum ponto da função de produção, sendo admitidas apenas ineficiências na escolha da escala de produção. No mundo real, é bastante plausível esperar que algumas firmas encontrem restrições até mesmo para operar sobre a função de produção. ${ }^{6}$ Além disso, mesmo que a firma deseje maximizar seu lucro e/ou minimizar seu custo total de produção, ela pode encontrar restrições de ordem tecnológica, gerencial e/ou institucional para tal, o que a impossibilitaria de alcançar seus objetivos econômicos (LEIBENSTEIN, 1966).

As situações expostas no parágrafo anterior ilustram a possibilidade de existirem ineficiências técnica e econômica dentro das firmas, cabendo à teoria econômica incorporar essas possibilidades em seus modelos de análise. Nesse sentido, a teoria das fronteiras de eficiência, desenvolvida a partir dos trabalhos seminais de Koopmans (1951), Debreu (1951) e Farrell (1957), tem a preocupação central de construir fronteiras de eficiência e, a partir destas, calcular/estimar os índices de ineficiência das firmas que não operam sobre as fronteiras. As fronteiras de produção, custo e lucro funcionam como um benchmarking com o qual podem ser comparados os desempenhos produtivos e econômicos de diferentes firmas da mesma indústria.

Se o objetivo da firma (ou o objetivo que o pesquisador definiu para a firma) for minimizar o custo total de produção, a medida de eficiência econômica de custo pode ser obtida pela razão entre o custo total mínimo para operar determinado volume de produção e o custo total da firma ao operar esse mesmo volume de produção. A medida de eficiência de custo pode ser desmembrada em dois componentes: (i) eficiência técnica

6. Uma firma que não opera sobre a função de produção não produz o máximo de produto que seria possível com a dotação de fatores utilizada e a tecnologia disponível. orientada para o uso dos fatores/insumos e (ii) eficiência alocativa. A eficiência técnica orientada para os insumos implica em operar determinado nível de produção com a menor dotação possível de fatores diante da tecnologia de produção disponível. A eficiência alocativa, por sua vez, ocorre quando a firma escolhe a combinação ótima dos fatores de produção diante dos preços relativos dos mesmos. Nesse ponto, a inclinação da tangente da isoquanta (relação entre os produtos marginais dos fatores) é igual à inclinação da isocusto (relação entre os preços dos fatores).

O problema da eficiência em custo é semelhante ao problema microeconômico de encontrar as demandas condicionadas pelos fatores de produção $\left(x_{1}{ }^{\mathrm{c}}, x_{2}{ }^{\mathrm{c}}, x_{\mathrm{n}}{ }^{\mathrm{c}}\right)$. Quando a firma escolhe suas demandas condicionadas ótimas, ela opera ao menor custo possível para determinado nível de produção. Portanto, a firma eficiente em custo deve escolher suas demandas condicionadas observando as características da tecnologia de produção, os preços dos fatores $\left(w_{1}, w_{2}, w_{\text {n }}\right)$ e o nível do produto $(y)$, de forma a operar esse nível de produção alcançando o menor custo total possível. Já a firma ineficiente em custos encontra limitações; seja para fazer a melhor combinação possível dos fatores diante de seus preços relativos (ineficiência alocativa), seja para minimizar o uso dos fatores para dado nível de produção (ineficiência técnica) (COELLI et al., 1998).

Para formalizar o exposto no parágrafo anterior, suponha uma firma operando em um mercado concorrencial que objetiva minimizar seu custo total para determinado nível de produção. Assumindo que a firma opera com o uso de dois fatores de produção ${ }^{7}\left(x_{1}\right.$ e $\left.x_{2}\right)$ para produzir o nível de produto $y$ e depara-se com os preços dos fatores $w_{1}$ e $w_{2}$, tem-se o seguinte problema de otimização condicionada:

$$
\begin{aligned}
& \operatorname{MinC}=w_{1} x_{1}+w_{2} x_{2} \\
& \text { S.a.: } y=f\left(x_{1}, x_{2}\right)
\end{aligned}
$$

7. O mesmo raciocínio pode ser adotado para o caso de mais fatores de produção. O exemplo aqui apresentado utiliza o caso de dois fatores para fins de simplificação. 
O lagrangiano para esse problema pode ser definido como:

$$
L=w_{1} x_{1}+w_{2} x_{2}+\lambda\left(y-f\left(x_{1}, x_{2}\right)\right)
$$

Diferenciando-se a equação (2) com relação a $x_{1}, x_{2}$ e l, tem-se:

$$
\begin{aligned}
& \frac{\partial L}{\partial x_{1}}=w_{1}-\lambda \frac{\partial y}{\partial x_{1}}=0 \\
& \frac{\partial L}{\partial x_{2}}=w_{2}-\lambda \frac{\partial y}{\partial x_{2}}=0 \\
& \frac{\partial L}{\partial \lambda}=y-f\left(x_{1}, x_{2}\right)=0
\end{aligned}
$$

Dividindo-se a equação (3) pela equação (4) é satisfeita a condição de primeira ordem de que a relação entre os preços dos fatores deve ser igual à relação entre os produtos marginais dos fatores (condição de equilíbrio). Em termos matemáticos, tem-se:

$$
\frac{w_{1}}{w_{2}}=\frac{\frac{\partial y}{\partial x_{1}}}{\frac{\partial y}{\partial x_{2}}}=\frac{\operatorname{Pmg} x_{1}}{\operatorname{Pmg} x_{2}}
$$

A firma que atende essa condição é alocativamente eficiente, ou seja, aloca os fatores de forma ótima dados os preços relativos dos mesmos. A partir de (6) é possível perceber que a condição de equilíbrio implica que, para que o custo total seja minimizado, a relação entre o valor gasto (em $\mathrm{R} \$$ ) e a produtividade marginal deve ser a mesma para todos os fatores de produção. Caso essa condição não seja atendida, a firma pode alterar a alocação dos fatores e reduzir seu custo total, ou seja, não está operando com custo total mínimo.

A solução da condição de equilíbrio (equação 6) para $x_{1}$ ou $x_{2}$ e a posterior substituição na equação (5) resulta nas funções de demanda condicionadas dos fatores de produção. ${ }^{8}$ Essas funções mostram a escolha ótima dos fatores $x_{1}$ e $x_{2}$ diante

8. Demandas condicionadas pelo fato de estarem condicionadas a determinado nível de produção escolhido pela firma. de seus preços e do nível de produção escolhido pela firma. Assim, tem-se que $x_{1}{ }^{\mathrm{c}}=f\left(w_{1}, w_{2}, y\right)$ e $x_{2}{ }^{\mathrm{c}}=f\left(w_{1}, w_{2}, y\right)$ em que $x_{1}{ }^{\mathrm{c}}$ é a demanda condicionada pelo fator $x_{1}$ e $x_{2}{ }^{\mathrm{c}}$ é a demanda condicionada pelo fator $x_{2}$. Substituindo-se as funções de $x_{1}{ }^{\mathrm{c}} \mathrm{e}$ $x_{2}{ }^{\mathrm{c}}$ na função objetivo do problema de otimização, é encontrada a função de custo, que depende do nível de produção escolhido pela firma e dos preços dos fatores de produção pagos pela firma: $C=f\left(w_{1}, w_{2}, y\right) \cdot{ }^{9}$ Essa função genérica mostra o custo total mínimo para cada nível de produção escolhido pela firma. ${ }^{10} \mathrm{O}$ seja, essa função microeconômica de custo é uma fronteira de custo.

Para decompor a ineficiência de custo em seus componentes de ineficiência alocativa e técnica, é necessário formalizar a representação da fronteira de custo. Supondo que as firmas se deparam com os preços dos fatores $w=\left(w_{1}, \ldots, w_{\mathrm{N}}\right) \in R_{{ }_{++}}^{\mathrm{N}_{+}}$ e objetivam minimizar o custo total de produção, tem-se, conforme apresentado anteriormente, que a função de custo mínimo ou fronteira de custo é definida como:

$$
c(y, w)=\min _{\mathrm{x}}\left\{w^{\mathrm{T}} x: D_{\mathrm{I}}(y, x) \geq 1\right\}
$$

A medida de eficiência de custo é então obtida pela razão entre o custo total mínimo e o custo total observado da firma:

$$
C E(x, y, w)=c(y, w) / w^{\mathrm{T}} x
$$

Essa medida assumirá valor menor ou igual a um, sendo o valor unitário possível apenas quando o custo total da firma for igual ao custo total mínimo de produção, o que, por sua vez, indica que a firma é eficiente em custo. A medida de eficiência alocativa dos fatores de produção pode ser obtida a partir da medida de eficiência de custo:

9. Quando a firma encontra limitações para alterar a dotação de um ou mais fatores de produção, situação bastante comum no curto prazo, as quantidades físicas desses fatores irão aparecer em sua função custo no lugar dos preços de tais fatores.

10. Na apresentação acima, não foi assumida forma funcional para a função de produção e, consequentemente, para a função de custo. Nas estimações econométricas, é necessário que se especifique a priori uma forma funcional. A próxima seção do trabalho irá tratar da forma funcional translog. 


$$
A E_{\mathrm{I}}(x, y, w)=C E(x, y, w) / T E_{\mathrm{I}}(y, x)^{11}
$$

As medidas de eficiência técnica e alocativa que compõem a eficiência de custo também apresentam valores menores ou iguais a um, com o valor unitário indicando firmas eficientes. É importante observar que a eficiência de custo é o produto da eficiência técnica com a eficiência alocativa $\left(C E=T E_{\mathrm{I}} \times A E_{\mathrm{I}}\right)$. A Figura 1 apresenta a decomposição da eficiência de custo em eficiência técnica e eficiência alocativa.

Figura 1. Decomposição da eficiência de custo

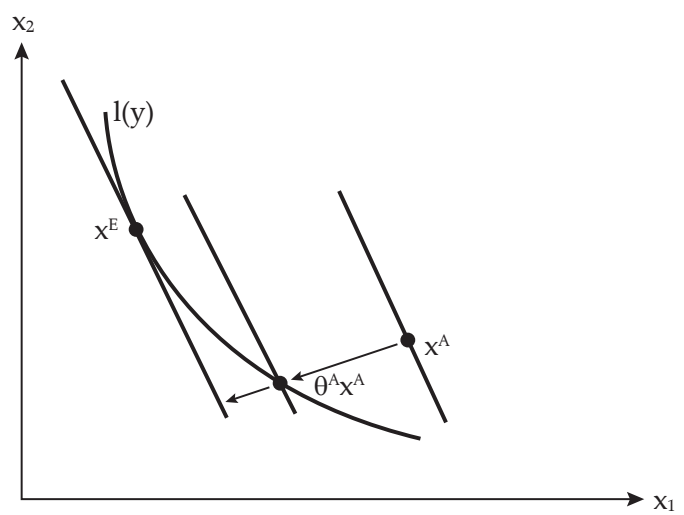

Fonte: Fried et al. (2008).

$\mathrm{O}$ vetor de fatores de produção $x^{\mathrm{E}}$ minimiza $\mathrm{o}$ custo total de produzir o vetor de produto $y$, dados os preços dos fatores $w$ e a tecnologia de produção disponível. $\mathrm{O}$ vetor de fatores $x^{\mathrm{E}}$ está no ponto de tangência da isoquanta $I(y)$ com a linha de isocusto, ou seja, nesse ponto a relação entre os produtos marginais dos fatores de produção é igual à relação entre os preços pagos pelos fatores. Portanto, dados os preços dos fatores de produção, $w^{\mathrm{T}} x^{\mathrm{E}}$ é o custo mínimo de produção do vetor de produto $y$. A firma que utiliza $\mathrm{o}$ vetor de fatores de produção $x^{\mathrm{A}}$ possui ineficiência técnica e alocativa no processo produtivo. A ineficiência técnica pode ser representada pela distância entre $x^{\mathrm{A}}$ e $\theta^{\mathrm{A}} x^{\mathrm{A}}$. Nesse caso, pode-se verificar que, diante da tecnologia de produção disponível, a firma poderia

11. $T E_{I}$ refere-se à eficiência técnica orientada para o uso mínimo dos fatores de produção. É evidente que, para calcular a eficiência de custo e a eficiência alocativa, será necessário calcular também a eficiência técnica orientada para o uso mínimo dos fatores de produção. reduzir o uso dos fatores $x_{1}$ e $x_{2}$ e ainda continuar operando o mesmo nível de produção. Por sua vez, a ineficiência alocativa é representada pela distância entre $\theta^{\mathrm{A}} x^{\mathrm{A}}$ e $x^{\mathrm{E}}$. A ineficiência alocativa reflete a inabilidade da firma em encontrar a combinação ótima dos fatores diante de seus preços relativos, ou seja, a firma poderia se mover ao longo da isoquanta $I(y)$ de forma a encontrar as demandas dos fatores minimizadoras do custo total de produção (demandas condicionadas dos fatores). A distância total de $x^{\mathrm{A}}$ até $x^{\mathrm{E}}$ reflete a ineficiência de custo da firma representada na Figura 1.

\subsection{Forma funcional translog}

Conforme exposto na subseção anterior, a lógica que fundamenta as análises de eficiência tem seus pilares na teoria microeconômica neoclássica, sendo, no entanto, os desvios das firmas com relação à função imposta para representar a tecnologia de produção admitidos e tratados como ineficiência. Assim, para estimar uma fronteira de custo, é necessário impor uma forma funcional a essa fronteira. A forma funcional flexível translog, desenvolvida por Christensen et al. (1971, 1973), tem sido amplamente utilizada na literatura de economia agrícola para representar a tecnologia de produção das propriedades rurais (GARCIA e FERREIRA FILHO, 2005; GOMES e FERREIRA FILHO, 2007; CONTE e FERREIRA FILHO, 2007).

A função custo translog pode ser escrita como:

$$
\begin{aligned}
\ln C(w, y)= & \beta_{0}+\sum_{i}^{n} \beta_{i} \ln w_{i}+\beta_{y} \ln y+ \\
& \frac{1}{2} \sum_{i}^{n} \sum_{j}^{n} \beta_{i j} \ln w_{i} \ln w_{j}+ \\
& \sum_{i}^{n} \beta_{i y} \ln w_{i} \ln y+\frac{1}{2} \beta_{y y}(\ln y)^{2}
\end{aligned}
$$

em que $\beta$ 's são os parâmetros estruturais da função custo, $w$ são os preços dos fatores, $y$ é o produto $\mathrm{e}$ os índices $i$ e $j$ representam os fatores de produção. A função custo translog deve atender a condição de simetria. Pelo teorema de Young, tem-se que $\beta_{\mathrm{ij}}=\beta_{\mathrm{ji}}$ para $i \neq j$.

Por sua vez, a homogeneidade linear nos preços dos fatores de produção é definida como: $\lambda C\left(y, w_{1}\right.$, $\left.w_{2}, \ldots, w_{\mathrm{n}}\right)=C\left(y, \lambda w_{1}, \lambda w_{2}, \ldots, \lambda w_{\mathrm{n}}\right)$. A homogeneidade 
nos preços implica que, para dado nível de produção, se todos os preços aumentarem em determinada proporção ( $1 \%$, por exemplo), o custo total das firmas deve aumentar nessa mesma proporção. Essa propriedade teórica implica que:

$\sum_{i}^{n} \beta_{i}=1 ; \sum_{i}^{n} \beta_{i y}=\sum_{i}^{n} \beta_{i j}=\sum_{j}^{n} \beta_{i j}=\sum_{i}^{n} \sum_{j}^{n} \beta_{i j}=0$

Para impor a homogeneidade nos preços dos fatores em estimativas econométricas, deve-se dividir o custo e o preço dos outros fatores pelo preço de um fator qualquer. $\mathrm{O}$ preço do fator de produção utilizado para impor a homogeneidade não entra diretamente na estimativa da função. No entanto, como a condição de homogeneidade linear nos preços indica que $\sum_{i}^{n} \beta_{i}=1$, o parâmetro do preço utilizado para impor a homogeneidade deve, obrigatoriamente, ser igual à unidade menos o somatório dos outros parâmetros associados aos preços dos fatores. Os parâmetros de segunda ordem do fator adotado para impor a homogeneidade na função podem igualmente ser obtidos a partir da condição $\sum_{i}^{n} \beta_{i y}=\sum_{i}^{n} \beta_{i j}=\sum_{j}^{n} \beta_{i j}=\sum_{i}^{n} \sum_{j}^{n} \beta_{i j}=0$.

Binswanger (1974) destaca que a homogeneidade nos preços dos fatores na função custo translog não impõe homogeneidade de grau um nos fatores na função de produção dual. Portanto, não são impostas restrições nas elasticidades de substituição entre os fatores ou nas elasticidades preço da demanda dos fatores, o que torna a função translog mais flexível do que outras formas funcionais da teoria microeconômica.

As propriedades de monotonicidade e concavidade nos preços dos fatores devem ser conferidas localmente na função custo translog. A condição de monotonicidade é satisfeita se as parcelas de custo forem não negativas. De acordo com Chambers (1988), a condição de concavidade nos preços dos fatores é satisfeita se a matriz Hessiana for negativa semidefinida. ${ }^{12}$ Portanto,

12. A condição necessária para que a matriz Hessiana seja negativa semidefinida é que todos os seus elementos diagonais sejam não positivos. Já a condição suficiente é que o primeiro menor principal seja não positivo e todos os outros menores principais alternem de sinal (CHAMBERS, 1988). em estimativas empíricas, é necessário calcular as segundas derivadas da função custo translog, montar a matriz Hessiana e calcular seus menores principais para checar a condição de concavidade nos preços dos fatores de produção. ${ }^{13}$

Pode-se calcular as demandas condicionadas dos fatores e as parcelas ótimas de custo pela teoria da dualidade. Aplicando-se o lema de Shephard na função custo translog, tem-se:

$$
\begin{aligned}
& x_{i}^{c}(w, y)=\frac{\partial C(w, y)}{\partial w_{i}}=\frac{\partial \ln C(w, y)}{\partial \ln w_{i}} \frac{C}{w_{i}}= \\
& \left(\beta_{i}+\sum_{j}^{n} \beta_{i j} \ln w_{j}+\beta_{i y} \ln y\right) \frac{C}{w_{i}}
\end{aligned}
$$

em que $x_{i}^{c}$ é a demanda condicionada pelo fator $x_{\mathrm{i}}$. A partir de (12), é possível calcular a parcela ótima de custo do fator $x_{\mathrm{i}}$ (denominada $S_{\mathrm{i}}$ ), ou seja, a participação ótima do fator $x_{\mathrm{i}}$ no custo total de produção da firma:

$$
S_{i}(w, y)=\frac{w_{i} x_{i}^{C}}{C}=\beta_{i}+\beta_{i y} \ln y+\sum_{j}^{n} \beta_{i j} \ln w_{j}
$$

É possível também calcular as elasticidades parciais de substituição entre os fatores e a elasticidade preço de cada fator de produção. Existem diferentes medidas de elasticidade de substituição e preço na literatura microeconômica, sendo a elasticidade de substituição parcial de Allen bastante utilizada em estudos empíricos (CHRISTENSEN e GREENE, 1976). Essa medida mostra o efeito de alterações no preço de um fator $\left(w_{\mathrm{j}}\right.$, por exemplo) sobre a quantidade utilizada de outro fator $\left(x_{\mathrm{i}}\right.$, por exemplo), mantendo-se os preços dos demais fatores e a produção constantes. A partir das medidas de elasticidade de substituição, podem-se verificar as possibilidades de troca entre os fatores permitidas pela tecnologia de produção, o que, por sua vez, é de grande utilidade para as firmas adaptarem-se às alterações que ocorrem nos preços dos fatores.

13. Conte e Ferreira Filho (2007) mostram que a condição de concavidade nos preços da função custo pode também ser verificada por meio dos sinais das elasticidades diretas dos fatores de produção, que devem ser todos negativos. 
Conforme apresentado em Christensen e Greene (1976), podem-se calcular as elasticidades parciais de substituição de Allen $\left(\sigma_{\mathrm{ij}}\right)$ como:

$$
\begin{aligned}
& \sigma_{i j}=\left(\beta_{i j}+S_{i} S_{j}\right) / S_{i} S_{j} \\
& \sigma_{i i}=\left[\beta_{i i}+S_{i}\left(S_{i}-1\right)\right] / S_{i}^{2}
\end{aligned}
$$

A equação (15) é importante para calcular a elasticidade preço da demanda do próprio fator $\left(\eta_{\mathrm{ii}}\right)$, como segue:

$$
\eta_{i i}=\sigma_{i i} S_{i}
$$

Essa medida mostra a variação percentual na quantidade demandada do fator i como resposta a variações percentuais em seu próprio preço.

O índice de economias de escala (IES), medida de grande interesse para o presente estudo, é calculado subtraindo-se a elasticidade custo (EC) da unidade. Na função custo translog, têm-se a seguinte equação:

$$
\begin{aligned}
\text { IES }= & 1-\frac{\partial \ln C(w, y)}{\partial \ln y}= \\
& 1-\left(\beta_{y}+\beta_{y y} \ln y+\sum_{i}^{n} \beta_{i y} \ln w_{i}\right)
\end{aligned}
$$

É notório a partir de (17) que o IES na função custo translog varia conforme o nível de produção, podendo, portanto, ser calculado para as diferentes escalas de operação das firmas de uma mesma indústria.

A partir da função custo translog em sua forma original (equação 10), é possível impor as restrições de homoteticidade, homogeneidade e elasticidades de substituição unitárias (CHRISTENSEN e GREENE, 1976). Uma função custo corresponde a uma estrutura de produção homotética apenas se for possível escrevê-la como uma função separada em termos do produto $(y)$ e dos preços dos fatores $\left(w_{\mathrm{i}}\right)$. Assim, deve-se fazer com que os parâmetros $\beta_{\text {iy }}$ (parâmetros de interação do produto com os preços dos fatores) da função translog sejam iguais a zero. Em uma estrutura de produção homotética, pode ainda ser imposta a restrição de homogeneidade. Para isso, a elasticidade custo deve ser constante em todos os pontos de dados (não variar com a produção e com o uso dos fatores). Desta forma, a condição de homogeneidade é imposta quando $\beta_{\text {iy }}$ e $\beta_{y y}$ são iguais a zero. Por fim, para fazer com que as elasticidades de substituição entre os fatores sejam iguais a zero, basta eliminar os termos de segunda ordem dos preços dos fatores na função custo translog $\left(\beta_{\mathrm{ij}}=0\right)$. Impondo as três condições na função translog, retorna-se à forma funcional Cobb-Douglas.

\section{Metodologia}

\subsection{Amostra e variáveis de análise}

Devido à grande representatividade do estado de São Paulo na produção citrícola brasileira (74\% do total produzido em 2013), a amostra desse estudo está concentrada nesse estado. Para calcular o tamanho da amostra de propriedades citrícola, utilizou-se a divisão regional proposta por Neves (2010), que divide a citricultura do estado de São Paulo em 5 regiões: Noroeste, Norte, Centro, Sul e Castelo..$^{14}$ A partir dessa divisão, foram selecionadas as regiões Central, Sul e Norte que, segundo dados do Lupa (2007), compreendem 9.370 propriedades rurais com produção de laranja (50\% do total no estado). Para calcular o tamanho da amostra, adotou-se o critério de amostragem aleatória simples. ${ }^{15}$ Com erro amostral de $10 \%$ e nível de confiança de $95 \%$, foi necessário obter uma amostra de 97 propriedades rurais. Durante a realização da pesquisa de campo, obteve-se uma amostra de 100 propriedades rurais. No entanto, devido a inconsistências em algumas informações, duas propriedades foram excluídas da amostra. Assim, a amostra final consistiu em 98 propriedades com produ-

14. Essa região foi assim classificada pela sua proximidade com a Rodovia Castelo Branco.

15. A fórmula utilizada para o cálculo do tamanho mínimo necessário da amostra é: $n=\frac{z^{2} \cdot p \cdot q \cdot N}{E^{2} \cdot(N-1)+Z^{2} \cdot p \cdot q} \mathrm{em}$ que $n$ é o tamanho da amostra; $Z$ é a abscissa da curva normal padrão, fixado um nível de confiança; $N$ é o tamanho da população; $E$ é o erro amostral admitido, expresso em decimais; $p$ é a estimativa verdadeira da proporção de um dos níveis da variável escolhida, sendo que normalmente adota-se o valor de 0,5 para $p$ quando não se tem essa informação e $q=1-p$. 
ção citrícola localizadas nas regiões Central, Sul e Norte do estado de São Paulo.

A coleta de dados foi feita no âmbito de um projeto de pesquisa financiado pela Fundação de Amparo à Pesquisa do Estado de São Paulo (Fapesp). Os dados, referentes ao ano safra 2013/14 (cross section), foram coletados pessoalmente por meio de observações em campo e da aplicação de um questionário estruturado junto aos citricultores durante o período de março a setembro de 2014. O questionário foi dividido em três blocos: a) características estruturais da produção (uso de fatores, produção e tecnologia); b) aspectos de comercialização (preços e estruturas de governança) e c) características dos produtores.

A descrição das variáveis utilizadas para estimar as fronteiras de custo pode ser observada no Quadro 1. Vale destacar que alguns gastos relevantes, como por exemplo, custos de formação do pomar, custos de transporte, custo de seguros e financiamentos e custos de oportunidade não foram incluídos na função custo devido à dificuldade e/ou subjetividade em apurá-los. Estudos empíricos que estimaram funções de custo adotaram essa mesma estratégia devido aos mesmos problemas (MOSHEIM e LOVELL, 2009). As principais pretensões das estimativas econométricas de funções de custo são inferir questões relacionadas à tecnologia de produção (índices de economias de escala, elasticidades de substituição dos fatores etc). Quando adota-se a abordagem de fronteiras de eficiência de custo, objetiva-se também identificar problemas na alocação ótima e no uso dos fato- res de produção pelas firmas. Assim, vale ressaltar que, ao contrário de estimativas contábeis de custo, os custos apurados para o presente estudo não têm a pretensão de apontar exatamente o gasto para se produzir uma caixa de laranja, mas sim de mostrar as características da tecnologia de produção e os diferenciais de eficiência na alocação de fatores de produção pelas propriedades rurais. Portanto, ao analisar os resultados do trabalho, o leitor deve prender-se mais às medidas econômicas obtidas a partir dos coeficientes e aos índices de eficiência econômica estimados do que aos valores de custo das propriedades rurais propriamente ditos.

Verifica-se, a partir do Quadro 1, que foi construída uma variável denominada "dispêndio" para as estimativas econométricas da função custo. Essa variável consiste na agregação dos gastos com defensivos e fertilizantes. Foi necessário agregar tais gastos e construir um índice de preço médio por planta produtiva devido a problemas de multicolinearidade e heterocedasticidade que estavam distorcendo os resultados da fronteira de custo quando os preços desses fatores de produção eram estimados de forma separada. A estratégia de agregação é bastante comum em análises econométricas de custo e há vários exemplos de estudos que adotaram essa estratégia na literatura de economia agrícola (GOMES e FERREIRA FILHO, 2007; CONTE e FERREIRA FILHO, 2007; MOSHEIM e LOVELL, 2009). Ademais, o custo de oportunidade relacionado ao uso da terra não foi incluído como variável exógena na função custo devido à sua alta correlação com a produção, o

Quadro 1. Variáveis adotadas para estimar as fronteiras de eficiência de custo das propriedades rurais

\begin{tabular}{|l|l|}
\hline \multicolumn{1}{|c|}{ Variável } & \multicolumn{1}{c|}{ Descrição } \\
\hline Custo $(C)^{*}$ & $\begin{array}{l}\text { Gasto total com os fatores de produção mão de obra, capital, fertilizantes e defensivos (somatório } \\
\text { dos preços médios multiplicados pelas quantidades físicas utilizadas) }\end{array}$ \\
\hline Produção $(y)$ & Número de caixas de 40,8 kg de laranja produzidas na safra 2013/14 \\
\hline Preço da mão de obra $\left(w_{1}\right)$ & $\begin{array}{l}\text { Gasto total com mão de obra dividido pela quantidade de horas trabalhadas na safra 2013/14 = } \\
\text { preço da hora de trabalho }\end{array}$ \\
\hline Preço do capital $\left(w_{2}\right)$ & $\begin{array}{l}\text { Somatório dos gastos com manutenção, depreciação, óleo diesel e energia elétrica dividido pela } \\
\text { quantidade de horas máquina utilizada na safra 2013/14 = preço da hora máquina }\end{array}$ \\
\hline Dispêndio $\left(w_{3}\right)$ & $\begin{array}{l}\text { Gasto total com fertilizantes NPK + gasto total com defensivos (produtos fitossanitários) dividido } \\
\text { pelo número de pés de laranja em produção na safra 2013/14 }\end{array}$ \\
\hline
\end{tabular}

* Não estão incluídos custos com formação de pomar, custos associados ao uso da terra, custos de transporte e custos de oportunidade. 
Tabela 1. Estatísticas descritivas das variáveis utilizadas nas fronteiras de eficiência de custo

\begin{tabular}{lcccc}
\hline \multicolumn{1}{c}{ Variável } & Média & Desvio padrão & Mínimo & Máximo \\
\hline Custo $(C)$ & $925.449,02$ & $1.291 .540,71$ & 23.412 & 7.091 .490 \\
Produção $(y)$ & $59.281,91$ & $82.677,26$ & 600,00 & $500.000,00$ \\
Preço da mão de obra $\left(w_{1}\right)$ & 8,41 & 1,36 & 6,11 & 11,74 \\
Parcela mão de obra $\left(S_{1}\right)$ & 0,23 & 0,09 & 0,08 & 0,49 \\
Preço do capital $\left(w_{2}\right)$ & 18,37 & 3,01 & 12,1 & 26,35 \\
Parcela capital $\left(S_{2}\right)$ & 0,19 & 0,08 & 0,07 & 0,47 \\
Dispêndio $\left(w_{3}\right)$ & 5,32 & 2,16 & 0,93 & 11,57 \\
Parcela dispêndio $\left(S_{3}\right)$ & 0,58 & 0,13 & 0,18 & 0,83 \\
\hline
\end{tabular}

Fonte: Dados da pesquisa de campo.

que também gerou fortes problemas de multicolinearidade nos modelos econométricos. ${ }^{16}$

As estatísticas descritivas das variáveis adotadas para estimar a fronteira de custo podem ser observadas na Tabela 1. Além das variáveis utilizadas diretamente no modelo econométrico (custo, preço dos fatores e produção), também são apresentadas as parcelas de custo com relação a cada um dos fatores de produção.

Na média da amostra, o custo de produção foi de R\$ 955.449,02, com mínimo de R\$23.412, máximo de $\mathrm{R}$ \$ 7.091.490,00 e desvio padrão de $\mathrm{R} \$$ $1.291 .540,71$. A produção média, por sua vez, foi de 59.282 caixas de $40,8 \mathrm{~kg}$. Os gastos com defensivos e fertilizantes (variável dispêndio) representaram, na média da amostra, a maior parcela dos custos (58\%), sendo que o índice de preço médio dos defensivos e fertilizantes por planta em produção foi de $\mathrm{R} \$ 3,22$. A mão de obra representou, em média, $23 \%$ do custo das propriedades e o preço médio da hora de mão de obra foi de $\mathrm{R} \$$ 8,41 . O gasto médio por hora máquina foi de $\mathrm{R} \$$ 18,37 e o capital representou, em média, $19 \%$ do custo das propriedades. Se comparados os dados da Tabela 1 com as despesas de custeio da lavoura citrícola apuradas pela Conab (2013), verifica-se que as parcelas de custo com relação aos fatores apurados no presente estudo não diferem sig-

16. Foram estimados modelos econométricos utilizando-se os preços dos defensivos e fertilizantes como variáveis separadas, bem como adicionando-se o custo de oportunidade associado ao uso da terra como variável exógena. Contudo, tais modelos apresentaram sérios problemas de multicolinearidade e heterocedasticidade, sendo pouco recomendável adotá-los nas análises. nificativamente daquelas apuradas pela Conab (34,9\% para mão de obra, $42 \%$ para dispêndio e $16,3 \%$ para capital/operação com máquinas). ${ }^{17}$

\subsection{Modelo econométrico de fronteira estocástica de custo}

Os dados foram analisados a partir da estimativa econométrica de uma fronteira estocástica de custo. O modelo econométrico, em sua forma genérica, pode ser descrito como:

$$
\ln C_{i}=C\left(y_{i}, w_{i}, \beta\right)+v_{i}+u_{i}
$$

em que $C_{\mathrm{i}}$ é o custo total de produção da i-ésima firma; $C$ (.) é uma função custo apropriada (translog ou CobbDouglas, por exemplo); $y_{\mathrm{i}}$ é o logaritmo da produção da i-ésima firma; $w_{\mathrm{i}}$ é o vetor de logaritmos dos preços pagos pelos fatores de produção; $\beta$ é o vetor de parâmetros a serem estimados; $v_{\mathrm{i}}$ é o termo de erro aleatório e $u_{\mathrm{i}}$ é o termo de erro não negativo associado à ineficiência de custo da i-ésima firma. A medida de eficiência econômica de custo da i-ésima firma $\left(\mathrm{EE}_{\mathrm{i}}\right)$ pode então ser obtida pela razão entre o custo mínimo representado pela fronteira ( $\left.\operatorname{com} u_{\mathrm{i}}=0\right)$ e o custo da firma, o que resulta em:

$$
E E i=e^{-u_{i}}
$$

Especificou-se uma forma funcional translog para representar a tecnologia de produção. Assim, pode-se representar a fronteira de custo estimada como:

17. Para obter a planilha de custos da citricultura apurada pela Conab, acesse www.conab.gov.br 


$$
\begin{aligned}
\ln \left(\frac{C}{w_{3}}\right)= & \beta_{0}+\beta_{1} \ln \left(\frac{w_{1}}{w_{3}}\right)+\beta_{2} \ln \left(\frac{w_{2}}{w_{3}}\right)+\beta_{y} \ln _{y}+\beta_{11} 1 / 2 \ln \left(\frac{w_{1}}{w_{3}}\right)^{2}+\beta_{12} \ln \frac{w_{1}}{w_{3}} \ln \frac{w_{2}}{w_{3}}+ \\
& \beta_{22} 1 / 2 \ln \left(\frac{w_{2}}{w_{3}}\right)^{2}+\beta_{y 1} \ln \ln _{y} \frac{w_{1}}{w_{3}}+\beta_{y 2} \ln \ln _{y} \ln \frac{w_{2}}{w_{3}}+\beta_{y y} 1 / 2 \ln _{y}^{2}+v+u
\end{aligned}
$$

Percebe-se, a partir de (20), que a variável "dispêndio" $\left(w_{3}\right)$ foi utilizada para impor a condição de homogeneidade linear nos preços da função custo. ${ }^{18}$ Os parâmetros relacionados a essa variável são obtidos por diferença:

$$
\begin{aligned}
& \beta_{3}=1-\left(\beta_{1}+\beta_{2}\right) \\
& \beta_{13}=-\beta_{11}-\beta_{12} \\
& \beta_{23}=-\beta_{12}-\beta_{22} \\
& \beta_{33}=-\beta_{13}-\beta_{23} \\
& \beta_{y 3}=-\beta_{y 1}-\beta_{y 2}
\end{aligned}
$$

A partir da equação (20) é possível impor um conjunto de restrições na função translog. Para impor a condição de homoteticidade é necessário escrever a função custo separada em termos de produto e preço dos fatores $\left(\beta_{\mathrm{yi}}=0\right)$. Em uma função custo homotética, pode-se ainda impor a condição de homogeneidade fazendo com que a elasticidade custo com relação à produção seja constante $\left(\beta_{y y}=0\right)$. Além disso, é possível fazer com que as elasticidades de substituição entre os fatores sejam iguais à unidade eliminando os termos de interação entre os preços dos fatores $\left(\beta_{\mathrm{ij}}=0\right)$. Ao impor essas três restrições na função translog, retorna-se a uma função de custo do tipo Cobb-Douglas. A função Cobb-Douglas também foi estimada para fins de comparação dos resultados. Os parâmetros da equação (20) e da função CobbDouglas foram estimados por meio de procedimentos de máxima verossimilhança utilizando-se o software econométrico LIMDEP 10.

18. É importante mencionar que a variável adotada para impor a restrição de homogeneidade linear nos preços não interfere nos resultados dos parâmetros e índices de eficiência estimados.

\section{Análise dos resultados}

Os resultados do presente artigo estão divididos em duas subseções. A primeira faz uma análise da tecnologia de produção a partir dos parâmetros estimados na fronteira de custo translog. Na segunda subseção são analisados os índices de eficiência de custo das propriedades rurais.

\subsection{Características da tecnologia de produção e economias de escala}

A Tabela 2, a seguir, apresenta os resultados obtidos a partir das estimativas econométricas das fronteiras de custo Cobb-Douglas e translog.

Em ambos os modelos estimados, o parâmetro de variância $\gamma$ apresentou valor próximo de um e significância estatística ao nível de $1 \%$, o que, por sua vez, significa que o termo de ineficiência é importante para explicar os desvios das propriedades com relação às fronteiras de custo. Ademais, realizou-se o teste de razão de máxima verossimilhança (likelihood-ratio test) para testar a hipótese nula de que não há ineficiência de custo na produção de laranja das propriedades analisadas. ${ }^{19}$ No modelo translog, o valor do qui quadrado calculado excedeu o valor do qui quadrado tabelado a $1 \%$ de significância estatística, rejeitando fortemente a hipótese nula. Já no modelo Cobb-Douglas, a hipótese nula é rejeitada apenas ao nível de $10 \%$ de significância estatística. ${ }^{20}$ Ambos os testes estatísticos realizados para comparar o ajuste dos modelos aos dados (teste de razão de máxima

19. Caso a hipótese nula seja aceita, tem-se que $\gamma=0$ e, portanto, o modelo se reduz a um modelo tradicional de custo estimado pelo método dos Mínimos Quadrados Ordinários (MQO).

20. No modelo de custo Cobb-Douglas, o qui quadrado calculado apresentou valor de 2,567. No modelo translog, o qui quadrado foi de 8,856 . O qui quadrado tabelado com $5 \%$ de significância estatística é de 2,706 e, com 1\% de significância, de 5,412. 
Tabela 2. Fronteiras estocásticas de custo Cobb-Douglas e translog

\begin{tabular}{|c|c|c|c|c|}
\hline \multirow{2}{*}{ Variável } & \multicolumn{2}{|c|}{ Modelo 1: Cobb-Douglas } & \multicolumn{2}{|c|}{ Modelo 2: translog } \\
\hline & Parâmetro & $\operatorname{Pr}(>|z|)$ & Parâmetro & $\operatorname{Pr}(>|z|)$ \\
\hline Constante $\left(\beta_{0}\right)$ & 1,061 & $0,000^{* * *}$ & $-0,4413$ & $0,000 * * *$ \\
\hline $\ln w_{1}$ (preço mão de obra) $\left(\beta_{1}\right)$ & 0,005 & 0,966 & 0,0192 & 0,863 \\
\hline $\ln w_{2}$ (preço capital) $\left(\beta_{2}\right)$ & 0,684 & $0,000^{* * *}$ & 0,6232 & $0,000 * * *$ \\
\hline $\ln w_{3}$ (dispêndio) $\left(\beta_{3}\right)$ & 0,310 & $0,000^{* * *}$ & 0,3576 & $0,000 * * *$ \\
\hline $\ln y$ (produção) $\left(\beta_{y}\right)$ & 0,785 & $0,000^{* * *}$ & 0,8713 & $0,000 * * *$ \\
\hline $\ln w_{1} \times \ln w_{1}\left(\beta_{11}\right)$ & - & - & 0,1434 & 0,871 \\
\hline $\ln w_{1} \times \ln w_{2}\left(\beta_{12}\right)$ & - & - & 0,2217 & 0,811 \\
\hline $\ln w_{1} \times \ln w_{3}\left(\beta_{13}\right)$ & - & - & $-0,3651$ & 0,233 \\
\hline $\ln w_{2} \times \ln w_{2}\left(\beta_{22}\right)$ & - & - & $-0,7739$ & 0,464 \\
\hline $\ln w_{2} \times \ln w_{3}\left(\beta_{23}\right)$ & - & - & 0,5527 & $0,087^{*}$ \\
\hline $\ln w_{3} \times \ln w_{3}\left(\beta_{33}\right)$ & - & - & $-0,1882$ & 0,403 \\
\hline $\ln y \times \ln y\left(\beta_{y y}\right)$ & - & - & 0,0873 & $0,000^{* * *}$ \\
\hline $\ln y \times \ln w_{1}\left(\beta_{\mathrm{y} 1}\right)$ & - & - & $-0,0096$ & 0,910 \\
\hline $\ln y \times \ln w_{2}\left(\beta_{\mathrm{y} 2}\right)$ & - & - & $-0,0766$ & 0,463 \\
\hline $\ln y \times \ln w_{3}\left(\beta_{\mathrm{y} 3}\right)$ & - & - & 0,0862 & $0,041^{* *}$ \\
\hline \multicolumn{5}{|l|}{ Parâmetros de variância } \\
\hline$\sigma_{\mathrm{s}}^{2}$ & 0,236 & $0,000^{* * *}$ & 0,242 & $0,000^{* * *}$ \\
\hline$\gamma$ & 0,861 & $0,000^{* * *}$ & 0,981 & $0,000^{* * *}$ \\
\hline $\operatorname{var}(u) / \operatorname{var}(u)+\operatorname{var}(v)$ & 0,693 & - & 0,949 & \\
\hline Log-Likelihood & $-23,225$ & - & $-12,467$ & \\
\hline qui-quadrado & $2,567^{*}$ & - & $8,856^{* * *}$ & - \\
\hline Eficiência média & 0,726 & & 0,694 & \\
\hline $\mathrm{N}=98$ & & & & \\
\hline
\end{tabular}

*** Significativo a $1 \% ; * *$ Significativo a $5 \%$; Significativo a $10 \%$.

Fonte: Resultados da pesquisa.

verossimilhança e teste de Wald) indicam rejeição da hipótese nula de que o modelo translog se reduz ao modelo Cobb-Douglas com 1\% de significância estatística. Assim, o modelo translog é muito mais adequado para representar a tecnologia de produção e, consequentemente, o comportamento da função custo das propriedades rurais. Portanto, as análises foram realizadas assumindo-se uma tecnologia representada pela forma funcional translog.

No modelo de custo translog, sete dos 15 parâmetros estimados apresentaram significância estatística. Nesse modelo, é necessário checar a condição de monotonicidade por meio do cálculo das parcelas ótimas de custo a partir da função estimada. Por meio da equação (13), foram calculadas as parcelas ótimas de custo (estimadas) para a média da amostra, cujos resultados foram todos positivos, respeitando a condição de monotonici- dade: $S_{\mathrm{MO}}$ (parcela mão de obra) $=0,047(4,7 \%)$; $S_{\text {CAP }}($ parcela capital $)=0,581(58,1 \%)$ e $S_{\text {DISP }}$ (parcela defensivos + fertilizantes $)=0,372(37,2 \%)$.

Conforme apresentado na Tabela 1 , as parcelas de custo observadas foram, em média, de $22,9 \%$ para a mão de obra, $19,2 \%$ para o capital e $57,9 \%$ para os defensivos e fertilizantes (dispêndio). A comparação entre as parcelas de custo observadas e as parcelas ótimas de custo estimadas indica uma tendência de substituição entre capital e mão de obra na produção citrícola (intensificação em capital). O cálculo das elasticidades cruzadas de substituição permite observar que os fatores são, de fato, substitutos (equações 14 e 15, Quadro 2). Ou seja, dadas as características tecnológicas da atividade citrícola, é possível substituir um fator por outro no processo de produção das propriedades analisadas. 
Quadro 2. Estimativas das elasticidades de substituição (cruzadas e diretas) dos fatores mão de obra, capital e dispêndio

\begin{tabular}{|c|c|c|c|}
\hline & Mão de obra & Capital & Dispêndio \\
\hline Mão de obra & $-0,16$ & 3,74 & $-1,89$ \\
\hline Capital & & $-1,75$ & 1,35 \\
\hline Dispêndio & & & $-1,31$ \\
\hline
\end{tabular}

Fonte: Resultados da pesquisa.

Segundo Conte e Ferreira Filho (2007), a condição de concavidade nos preços da função custo translog será respeitada se as elasticidades diretas dos fatores apresentarem valor negativo. Percebe-se que todas as elasticidades diretas apresentaram valor negativo, confirmando que a função custo translog estimada respeita a condição de concavidade para a média da amostra. Em relação às elasticidades cruzadas, sinal positivo indica que os fatores são substitutos e sinal negativo indica relação de complementaridade entre os fatores no processo de produção. A relação de substituição indica que, quando o preço do fator $x_{i}$ aumenta, o fator $x_{j}$ (substituto de $x_{i}$ ) é utilizado com maior intensidade no processo produtivo. A relação de complementaridade, por sua vez, indica o contrário. Com base nos resultados do Quadro 2, nota-se que os fatores "mão de obra" e "capital" são substitutos no processo de produção de laranja. Ou seja, é possível trocar um fator pelo outro quando ocorrem alterações em seus preços relativos, conforme era esperado. Por sua vez, a relação entre os fatores "mão de obra" e "dispêndio" é de complementaridade. De fato, não se esperava que fosse possível substituir um pouco de trabalho por aplicações de adubos e defensivos (e vice-versa) quando ocorrem altera- ções nos preços relativos desses fatores. Por fim, a relação de substituição entre "capital" e "dispêndio" apresentou sinal contrário ao esperado. $\mathrm{O}$ sinal positivo mostra relação de substitubilidade, indicando que é possível substituir um pouco de capital por adubações e/ou aplicações de defensivos (e vice-versa) quando ocorrem alterações nos preços relativos desses fatores.

A partir dos parâmetros estimados na função custo translog, os índices de economias de escala (IES) foram calculados para cada uma das propriedades da amostra por meio da equação (17). A Tabela 3 apresenta os resultados obtidos, dividindo as 98 propriedades em seis grupos de acordo com diferentes faixas de IES.

Verifica-se que oito propriedades da amostra operam com deseconomias de escala, o que indica que a escala ótima de produção é menor do que a escala dessas propriedades. Entretanto, grande parte das propriedades da amostra $(91,8 \%)$ está operando na região de economias de escala.

As propriedades que operam com deseconomias de escala foram divididas em dois grupos: (I) região com deseconomias de escala acentuadas e (II) região com ligeiras deseconomias de escala. A propriedade com menor escala de produção dentre as propriedades do grupo I produziu, na

Tabela 3. Índices de economias de escala das propriedades rurais calculados a partir da fronteira de custo translog

\begin{tabular}{cccc}
\hline Grupo & Faixas de IES & Número de firmas & $\%$ \\
\hline I & $<-0,05$ & 3 & $3,1 \%$ \\
II & $-0,05$ a 0 & 5 & $5,1 \%$ \\
III & 0,001 a 0,05 & 4 & $4,1 \%$ \\
IV & 0,051 a 0,10 & 9 & $9,2 \%$ \\
V & 0,101 a 0,20 & 33 & $33,7 \%$ \\
VI & $>0,201$ & 44 & $44,9 \%$ \\
\hline
\end{tabular}

Fonte: Resultados da pesquisa. 
Tabela 4. Índices de economias de escala (IES) para diferentes níveis de produção de laranja

\begin{tabular}{|c|c|c|c|c|c|c|c|c|}
\hline & \multicolumn{8}{|c|}{ Grupo } \\
\hline & 1 & 2 & 3 & 4 & 5 & 6 & 7 & 8 \\
\hline Produção (mil caixas) & 8 & 21,52 & 44,9 & 78 & 108,17 & 144,05 & 243,73 & 361,25 \\
\hline IES & 0,30 & 0,21 & 0,16 & 0,11 & 0,08 & 0,05 & $-0,02$ & $-0,04$ \\
\hline
\end{tabular}

Fonte: Resultados da pesquisa.

safra 2013/14, 315.000 caixas de laranja; indicando que, a partir desse nível de produção, começam a surgir deseconomias de escala mais significativas. Já o grupo II possui propriedades com escalas de produção entre 200.000-300.000 caixas. Essas propriedades operam praticamente na região de escala ótima, apresentando IES muito próximos de zero. Por sua vez, as propriedades do grupo III, cujas escalas de produção estão entre 125.000 200.000 caixas, operam com economias de escala pouco significativas, isto é, também estão próximas à escala ótima de produção. Considerando os grupos II e III como os mais próximos à escala ótima, tem-se que apenas nove propriedades da amostra estão operando na região de custo médio mínimo. As propriedades do grupo IV, cujas escalas de produção encontram-se entre 65.000-125.000 caixas, operam em uma região onde já começam a surgir economias de escala mais relevantes. Essas propriedades já poderiam obter reduções consideráveis em seus custos médios aumentando o volume de produção. Por fim, as propriedades dos grupos V e VI estão operando com largas economias de escala. Todas essas propriedades possuem escala de produção inferior a 60.000 caixas/ano e poderiam aproveitar-se de significativas reduções de custo médio caso conseguissem produzir maiores volumes de laranja. Ao operar com maior escala de produção, essas propriedades poderiam aproveitar-se de possíveis vantagens na compra de insumos, bem como fazer um melhor uso de máquinas e instalações subutilizadas para pequenos volumes de produção de laranja. Dessa forma, nota-se que a grande parte da amostra opera em uma região de escala subótima. ${ }^{21}$

21. Existem diferentes fatores que podem impedir as firmas de operarem na região escala ótima, como por exemplo, imperfeições nos mercados de compra dos fatores e venda do produto, restrição ao crédito rural e baixa adoção de tecnologias.
Christensen e Greene (1976) adotaram um procedimento estatístico interessante para sintetizar e facilitar a apresentação dos resultados de IES. Os autores dividiram a amostra daquele estudo em grupos, de acordo com diferentes níveis de produção. Os IES foram então calculados para a média da produção e dos preços dos fatores de produção dentro de cada grupo. Esse procedimento permite que seja verificada a evolução do IES conforme alteram-se os níveis de produção, mantendo-se os preços dos fatores fixos para cada nível de produção. Para sintetizar as análises aqui realizadas, adotou-se o procedimento estatístico proposto por Christensen e Greene (1976) e os grupos de propriedades rurais foram divididos da seguinte forma: 1) produção entre 0 e 15.000 caixas (33 propriedades com média de 8.000 caixas); 2) 15.001-30.000 (15 propriedades com média de 21.518 caixas); 3) 30.001-55.000 (21 propriedades com média de 44.904 caixas); 4) 55.001-90.000 (11 propriedades com média de 78.000 caixas); 5) 90.001-130.000 (6 propriedades com média de 108.166 caixas); 6) 130.001-200.000 (5 propriedades com média de 144.052 caixas); 7) 200.001-300.000 (3 propriedades com média de 243.733 caixas); 8) 300.001550.000 (4 propriedades com média de 361.250 caixas). A Tabela 4 apresenta os IES para os oito grupos construídos.

Os resultados obtidos a partir do procedimento estatístico de Christensen e Greene (1976) estão bastante consistentes com aqueles apresentados na Tabela 3. Notam-se consideráveis economias de escala para baixos níveis de produção (grupos 1 e 2), as quais se reduzem gradualmente conforme a produção aumenta, até que, para o nível de produção de 200.000-300.000 caixas (grupo 7), começam a ocorrer deseconomias de escala. Os grupos 6 (produção de 130.000-200.000 
Figura 2. Curva de custo médio derivada da função custo translog

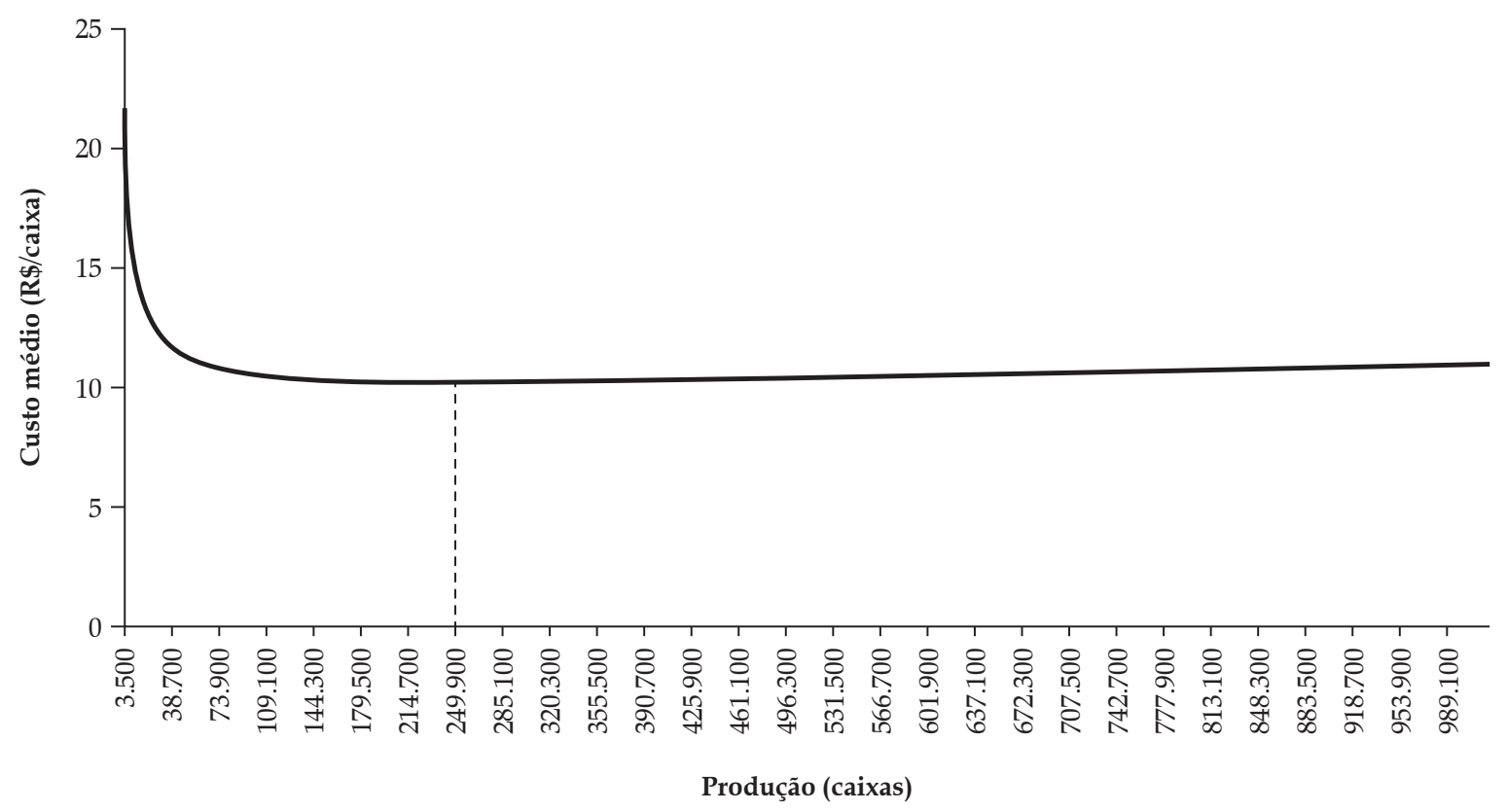

Fonte: Resultados da pesquisa.

caixas) e 7 (produção de 200.000-300.000 caixas) apresentam-se no limite entre a existência de economias e deseconomias de escala. Assim, pode-se inferir que a escala de custo médio mínimo (escala ótima) encontra-se nessa faixa de produção (130.000-300.000 caixas).

Por fim, é interessante evoluir a função de custo médio para diversos níveis de produção mantendo-se os preços dos fatores de produção fixos para a média da amostra. Esse procedimento resulta na tradicional curva de custo médio presente nos manuais de microeconomia. A curva de custo médio, calculada a partir dos parâmetros estimados na fronteira de custo trans$\log$, pode ser observada na Figura 2. Confirma-se o comportamento decrescente do custo médio para níveis baixos e médios de produção (faixa de economias de escala), seguido de um ponto de mínimo (escala ótima $=250.000$ caixas) e, após isso, comportamento ascendente do custo médio para altos níveis de produção (faixa de deseconomias de escala). A forte queda da curva de custo médio para níveis iniciais de produção confirma a existência de grandes economias de escala para pequenos níveis de produção (menores do que 25.000 caixas). Já as deseconomias de escala não se acentuam de forma tão forte.

O custo médio mínimo ( $\mathrm{R}$ 10,17/caixa) ocorre para o volume de 250.000 caixas de laranja (indicado na Figura 2 com a linha tracejada). Considerando a escala ótima de 250.000 caixas de laranja e o produto médio de 1.199 caixas por hectare (média da amostra de propriedades com eficiência superior a 90\%), tem-se que uma propriedade de tamanho ótimo (e economicamente eficiente) deve operar com uma área de, aproximadamente, 208,5 hectares de laranja com 94.058 pés de laranja em produção. ${ }^{22}$

\section{2. Índices de eficiência de custo}

Os índices de eficiência de custo, calculados a partir dos desvios das propriedades com relação às fronteiras de custo Cobb-Douglas e translog, são apresentados na Tabela 5 .

22. O número de pés em produção foi calculado a partir da multiplicação da média da amostra (451,12 pés/hectare) pela área de 208,5 hectares. 
Tabela 5. Índices de eficiência econômica de custo estimados a partir das fronteiras de custo Cobb-Douglas e translog

\begin{tabular}{lcc}
\hline $\begin{array}{c}\text { Faixas de eficiência/ } \\
\text { Número de propriedades }\end{array}$ & $\begin{array}{c}\text { Modelo 1: } \\
\text { Cobb-Douglas }\end{array}$ & $\begin{array}{c}\text { Modelo 2: } \\
\text { translog }\end{array}$ \\
\hline$<50 \%$ & 10 & 15 \\
$50-70 \%$ & 28 & 34 \\
$70,01-80 \%$ & 23 & 17 \\
$80,01-90 \%$ & 30 & 15 \\
$>90,01 \%$ & 7 & 17 \\
Eficiência média & 0,726 & 0,694 \\
Desvio padrão & 0,143 & 0,176 \\
Máximo & 0,923 & 0,971 \\
Mínimo & 0,417 & 0,317 \\
\hline Índice de correlação & & \\
* Significativo a 1\%. & $0,88^{*}$ & \\
Fonte: Resultados da pesquisa. & &
\end{tabular}

Percebe-se que, independente da forma funcional adotada, as propriedades da amostra podem reduzir consideravelmente o custo de produção de laranja utilizando os fatores de forma mais eficiente ou combinando-os melhor diante dos seus preços relativos. Considerando a tecnologia representada pelo modelo translog (mais adequado), os índices de eficiência de custo das propriedades rurais analisadas apresentaram-se entre o mínimo de $31,7 \%$ e o máximo de $97,1 \%$, com média de $69,4 \%$ e desvio padrão de $17,6 \%$. Neste modelo, a firma mais eficiente da amostra opera com possibilidade de reduzir seu custo em apenas 2,9\% diante da mesma produção e do mesmo vetor de preços pagos pelos fatores. Já a firma menos eficiente da amostra poderia operar com um custo de produção 68,3\% mais baixo caso utilizasse os fatores de forma mais eficiente e/ou combinasse-os de forma ótima diante de seus preços relativos. Ademais, verifica-se que, em média, as propriedades rurais analisadas poderiam reduzir o custo em consideráveis $30,6 \%$ apenas alterando a combinação dos fatores de produção e utilizando-os de forma mais eficiente. Neste sentido, percebe-se que há espaço significativo para economias de custo entre as propriedades.

As propriedades rurais foram divididas em diferentes classes de acordo com seus índices de eficiência de custo na Tabela 5. No modelo de custo translog, 17 propriedades rurais estão operando na faixa de alta eficiência econômica (índices superiores a 90\%). Essas propriedades operam muito próximas à fronteira de custo e já se encontram no limite das possibilidades de redução no custo de produção. As 15 propriedades que operam com eficiência de custo entre 80-90\% também estão relativamente próximas à fronteira de custo; entretanto, ainda possuem margem de redução de custo entre $10-20 \%$. Por outro lado, 49 propriedades operam com eficiência de custo inferior a $70 \%$, sendo muito crítica a situação das 15 propriedades que operam com eficiência de custo menor do que 50\% (faixa de baixa eficiência econômica). Essas propriedades poderiam melhorar de forma significativa seus resultados econômicos reduzindo a ineficiência em custo. Em um período de crise no mercado de venda do produto, operar com eficiência de custo é condição necessária para obter resultados econômicos satisfatórios (ou ao menos que permitam continuar na atividade).

Para melhor compreender as características operacionais das propriedades mais eficientes em custo, a Tabela 6 mostra alguns indicadores técnicos e econômicos das oito propriedades que apresentaram os maiores índices de eficiência de custo no modelo translog. 
Tabela 6. Características operacionais e econômicas das propriedades com maiores índices de eficiência de custo

\begin{tabular}{lcccccccc}
\hline & \multicolumn{1}{c}{ Propriedades } \\
\hline & 1 & 2 & 3 & 4 & 5 & 6 & 7 & 8 \\
\hline Eficiência & $97 \%$ & $95,8 \%$ & $95,4 \%$ & $95,1 \%$ & $95 \%$ & $94,5 \%$ & $94 \%$ & $93,2 \%$ \\
Custo (C) & 661,7 & 499,3 & 408,9 & 137,8 & 105,2 & 186,6 & $5.639,7$ & $1.285,7$ \\
C $^{*}$ & 642,3 & 478,7 & 390,1 & 131,0 & 99,9 & 176,3 & $5.300,4$ & $1.198,4$ \\
Produção (y) & 60.000 & 48.000 & 40.000 & 11.187 & 7.600 & 19.000 & 500.000 & 158.261 \\
Cme (C/y) & 11,03 & 10,40 & 10,22 & 11,32 & 13,84 & 9,82 & 11,28 & 8,12 \\
S $_{\text {MO }}$ & 0,11 & 0,11 & 0,13 & 0,15 & 0,10 & 0,14 & 0,16 & 0,15 \\
S $_{\text {CAP }}$ & 0,30 & 0,29 & 0,23 & 0,18 & 0,19 & 0,26 & 0,34 & 0,35 \\
S $_{\text {DISP }}$ & 0,59 & 0,60 & 0,64 & 0,67 & 0,71 & 0,60 & 0,50 & 0,50 \\
IES & 0,11 & 0,17 & 0,16 & 0,24 & 0,26 & 0,29 & $-0,06$ & 0,09 \\
\hline
\end{tabular}

Nota: O custo (C) está em R\$ milhares; $\mathrm{C}^{*}$ representa o custo ótimo (mínimo possível para a tecnologia de produção e preços dos fatores); Cme = custo médio (custo/produção); $\mathrm{S}_{\mathrm{MO}}, \mathrm{S}_{\mathrm{CAP}}$ e $\mathrm{S}_{\text {DISP }}$ são as parcelas do custo total com relação à mão de obra, capital e dispêndio, respectivamente; IES é o índice de economias de escala.

Fonte: Resultados da pesquisa.

Figura 3. Relação entre produção e eficiência de custo

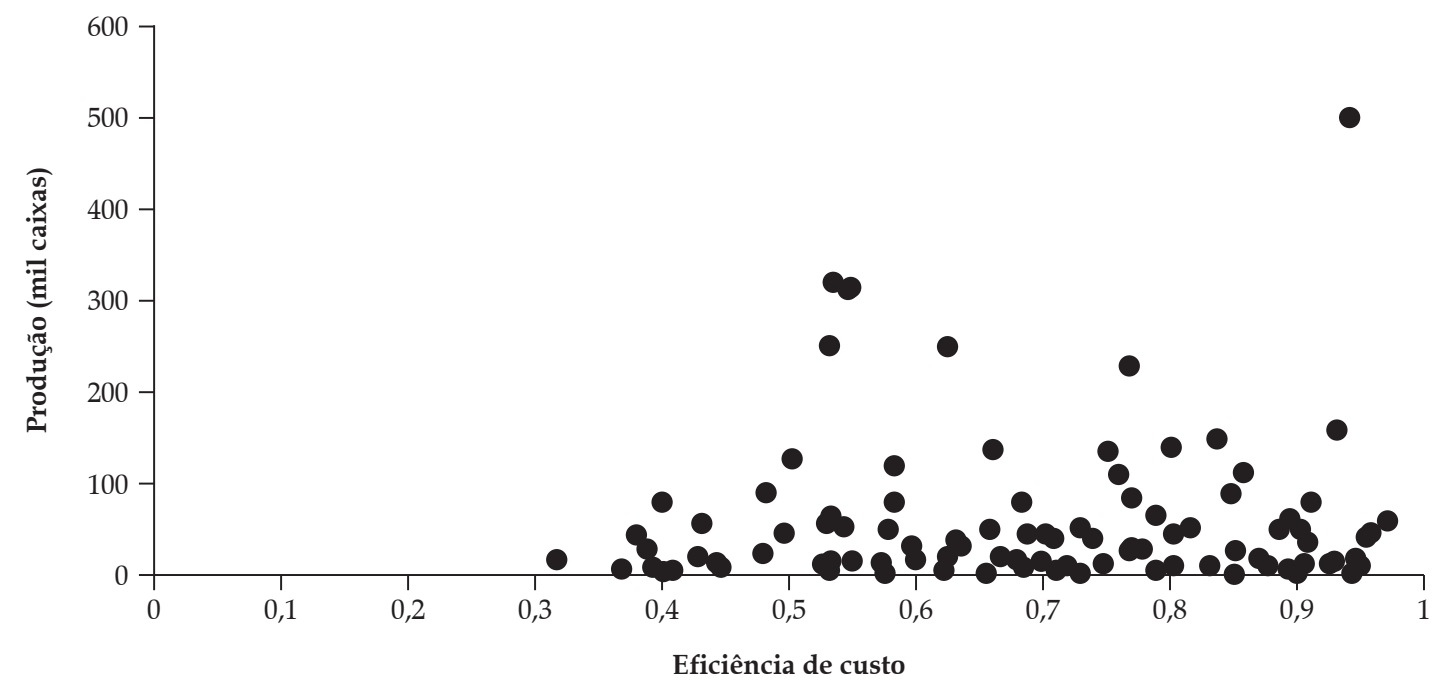

Fonte: Resultados da pesquisa.

Verifica-se que há propriedades com diversas escalas de produção operando próximas à fronteira de custo (7.600-500.000 caixas). Esse resultado mostra que, apesar de a tecnologia de produção possibilitar fortes economias de escala para baixos níveis de produção, é possível operar com eficiência de custo em diferentes tamanhos de firma. A Figura 3, ao relacionar a eficiência de custo com a produção das propriedades, confirma que há propriedades com pequena, média e grande escala operando em diferentes faixas de eficiência de custo.
É importante diferenciar novamente os conceitos de eficiência de custo e economias de escala. ${ }^{23}$ A medida de eficiência de custo é obtida a partir da relação entre o custo mínimo e o custo de produção observado da firma, dado o seu nível de produção e os preços dos fatores. Ou seja, mostra-se, para o nível de produção

23. Em uma tecnologia caracterizada por retornos constantes de escala para todos os níveis de produção, a eficiência de custo e o IES vão apresentar-se perfeitamente correlacionados. Nesse caso, quando a firma opera sobre a fronteira, ela também irá operar com custo médio mínimo. Isto é, quando eficiência de custo $=100 \%$, IES $=0$. 
escolhido pela firma, qual é o menor custo que ela poderia operar diante dos preços que paga pelos fatores. A medida de economia de escala, por sua vez, indica o tamanho ótimo que a firma deveria escolher para sua operação (eficiência de escala). Nesse caso, mostra-se qual é a escala de produção que retorna o menor custo médio possível, considerando-se as características da tecnologia de produção. Assim, uma firma pode perfeitamente operar sobre a fronteira de custo total mínimo (eficiência de custo $=1$ ) e ainda assim apresentar um IES alto ou negativo. Esse resultado indica a impossibilidade de redução no custo total para o nível de produção escolhido pela firma e diante dos preços dos fatores de produção que ela paga. Contudo, indica também que a firma poderia operar com um custo médio mais baixo caso alterasse seu tamanho (uso de fatores) e, consequentemente, seu nível de produção.

As propriedades 4, 5 e 6 da Tabela 6 operam próximas à fronteira de custo, entretanto, estão em uma região de fortes economias de escala. Apesar da pequena margem para reduzir o custo diante do nível de produção escolhido, essas três propriedades poderiam obter redução considerável no custo médio caso operassem com uma escala de produção maior. Por sua vez, a propriedade 7 opera com alta eficiência de custo e em uma região de deseconomias de escala. Essa propriedade poderia reduzir seu custo médio caso operasse com uma escala de produção menor. No entanto, para a produção escolhida, ela já está bastante próxima ao custo total (e médio) mínimo.

Por fim, se comparados os dados da Tabela 6 com aqueles apresentados na Tabela 1, pode-se constatar que as propriedades mais eficientes em custo estão avançadas no processo de substituição de mão de obra por capital. Para a média da amostra, a mão de obra representa $23 \%$, enquanto o capital representa 19\% do custo de produção (Tabela 1). Para as propriedades mais eficientes em custo, as participações da mão de obra e capital são, respectivamente, de $13 \%$ e $27 \%$. Ademais, a participação do dispêndio (fertilizantes + defensivos) no custo de produção é ligeiramente superior para a média das propriedades mais eficientes $(60 \%$ contra $58 \%$ para a média da amostra). Esses resultados mostram que, de uma forma geral, as propriedades devem intensificar o uso de capital na atividade citrícola.

\section{Conclusões}

O presente trabalho teve os objetivos de analisar a existência de economias de escala e ineficiência econômica na produção citrícola. Verificou-se, por meio da estimativa econométrica de uma fronteira de custo, a existência de economias de escala para níveis baixos de produção, as quais se esgotam para grandes volumes. A escala de custo médio mínimo encontra-se entre 150.000300.000 caixas de laranja, sendo que grande parte das propriedades da amostra opera com escala de produção inferior a essa. A eficiência média de custo apresentou valor de $69,4 \%$, o que mostra que há possibilidade de consideráveis economias de custo diante do mesmo nível de produção e dos mesmos preços pagos pelos fatores. Notou-se que, mesmo diante da existência de economias de escala para pequenos níveis de produção, há propriedades com baixa escala de produção operando com alta eficiência de custo. Ou seja, essas propriedades utilizam e alocam seus fatores de forma eficiente diante dos preços, do nível de produção e da tecnologia disponível. Nesses casos, é possível que a ineficiência de escala seja parcialmente compensada pela alta eficiência de custo. Portanto, propriedades rurais de pequeno porte podem buscar alternativas para a baixa eficiência de escala, como por exemplo, melhorar a alocação e uso dos fatores de produção. Ademais, as propriedades podem obter economias de custo intensificando o uso de capital na atividade, tendência já observada nas propriedades rurais mais eficientes em custo.

O estudo tem como principal limitação a não inclusão do custo de oportunidade associado ao uso da terra e de algumas outras despesas (formação do pomar, financiamentos e seguros). Contudo, optou-se pela parcimônia no modelo 
econométrico, na coleta de dados e na especificação das variáveis. Além disso, foi estimado um modelo econométrico que mostrou-se bem ajustado aos dados coletados e apresentou-se coerente com a teoria microeconômica, sendo possível utilizá-lo para os objetivos do trabalho. Estima-se que os custos aqui apurados representem entre $70-80 \%$ do custo total de produção das propriedades. Outra limitação é a não inclusão de custos ambientais no modelo econométrico, o que, diante da crescente preocupação da sociedade com essa questão, deve ser considerado em estudos futuros.

Como sugestão para estudos futuros, tem-se também a investigação dos fatores que explicam os diferenciais de eficiência de custo entre as propriedades citrícolas. Conforme Leibenstein (1966), é possível que fatores gerenciais, institucionais e de capital humano dos citricultores possam explicar os diferenciais de eficiência de custo, sendo interessante testar a relação entre esses fatores e os índices de eficiência das propriedades citrícolas.

\section{Referências}

AIGNER, D. J., LOVELL, C. A. K. e SCHMIDT, P. Formulation and estimation of stochastic frontier production function models. Journal of Econometrics, v. 6, p. 21-37, 1977.

BINSWANGER, H. P. A cost function approach to the measurement of factor demand elasticities and elasticities of substitution. American Journal of Agricultural Economics, v. 56, p. 377-386, 1974.

CHAMBERS, R. G. Applied production analysis: A dual approach. Cambridge University Press, 1988.

CHRISTENSEN, L. R. e GREENE, W. H. Economies of Scale in U.S. Electric Power Generation. The Journal of Political Economy, v. 84, n. 4, p. 655-676, 1976.

., JORGENSON, D. W. e LAU, L. J. Conjugate Duality and the Transcendental Logarithmic Production Function. Econometrica, v. 39, p. 255-256, 1971.

Transcendental Logarithmic Production Frontiers. The Review of Economics and Statistics, v. 55, n. 1, p. 28-45, 1973.
COELli, T. J., RAO, D. S. P. e BATTESE, G. E. An introduction to efficiency and productivity analysis. Kluwer Academic Press, 1998.

COMPANHIA NACIONAL DE ABASTECIMENTO - CONAB; COORDENADORIA DE ASSISTÊNCIA TÉCNICA - CATI; INSTITUTO DE ECONOMIA AGRÍCOLA - IEA. Acompanhamento da safra brasileira de laranja, terceiro levantamento. Brasília, 2013.

CONTE, L. e FERREIRA FILHO, J. B. S. Substituição de fatores produtivos na produção de soja no Brasil. Revista de Economia e Sociologia Rural, v. 45, n. 2, p. 475495, 2007.

COORDENADORIA DE DEFESA AGROPECUÁRIA CDA. Dados da Citricultura do Estado de São Paulo, 1ำ Semestre de 2012. Disponível em: <www.cda.gov.br>

DEBREU, G. The Coefficient of Resource Utilization. Econometrica, v. 19, n. 3, p. 273-292, 1951.

FAGUNDES, P. R. S. et al. Cultura da laranja no Estado de São Paulo, 2007/08. Informações Econômicas, v. 40, n. 9 , p. $54-67,2010$.

FARRELL, M. J. The measurement of productive efficiency. Journal of the Royal Statistical Society, v. 120, n. 3, p. 253-282, 1957.

FIGUEIREDO, A. M., SOUZA FILHO, H. M. e PAULILLO, L. F. O. Análise das margens e transmissão de preços no Sistema Agroindustrial do suco de laranja no Brasil. Revista de Economia e Sociologia Rural, v. 51, n. 2, p. 331-350, 2013.

FRIED, H. O., LOVELL, C. A. K. e SCHMIDT, S. S. Efficiency and Productivity. In: FRIED, H. O., LOVELL, C. A. K. e SCHMIDT, S. S. (Orgs.). The measurement of productive efficiency and productivity growth. New York: Oxford University Press, 2008, p. 1-106.

GARCIA, L. A. F. e FERREIRA FILHO, J. B. S. Economias de escala na produção de frangos de corte no Brasil. Revista de Economia e Sociologia Rural, v. 43, n. 3, p. 465483, 2005.

GOMES, A. L. e FERREIRA FILHO, J. B. S. Economias de escala na produção de leite: uma análise dos Estados de Rondônia, Tocantins e Rio de Janeiro. Revista de Economia e Sociologia Rural, v. 45, n. 3, p. 591-619, 2007.

IBGE - Instituto Brasileiro de Geografia e Estatística. Banco de dados agregados: Produção Agrícola Municipal 2013. Disponível em: <www.sidra.ibge.gov.br>.

IEA - Instituto de Economia Agrícola. Banco de dados: Estatísticas da Produção Agropecuária. Disponível em: $<$ http://ciagri.iea.sp.gov.br/>. 
KOOPMANS, T. C. An Analysis of Production as an Efficient Combination of Activities. In: KOOPMANS, T. C. (Org.). Activity Analysis of Production and Allocation. Cowles Commission for Research in Economics, Jone Wiley, New York, 1951.

LEIBENSTEIN, H. Allocative Efficiency vs. "X-Efficiency". The American Economic Review, v. 56, n. 3, p. 392-415, 1966.

LEVANTAMENTO CENSITÁRIO DAS UNIDADES DE PRODUÇÃO AGROPECUÁRIA DO ESTADO DE SÃO PAULO - LUPA 2007/08. Disponível em <http://www. cati.sp.gov.br/projetolupa $>$.
MOSHEIM, R. e KNOX LOVELL, C. A. Scale economies and inefficiency of U.S. dairy farms. American Journal of Agricultural Economics, v. 91, n. 3, p. 777-794, 2009.

NEVES, M. F. O retrato da citricultura brasileira. 1. ed. São Paulo: CitrusBR, 2010, 137p.

TURRA, C., VIAN, C. E. F., SOARES, A. F. e BINI, D. A. Análise socioeconômica e ambiental da citricultura no Estado de São Paulo. In: Congresso da Sociedade Brasileira de Economia, Administração e Sociologia Rural, 53, 2015, João Pessoa-PB. Anais... Brasília: Sociedade Brasileira de Economia, Administração e Sociologia Rural, 2015. 